\title{
Naturalismo, aqui e là-bas
}

\author{
Leonardo Mendes I UERJ \\ Pedro Paulo Garcia Ferreira Catharina I UFRJ
}

\begin{abstract}
Resumo: Neste ensaio, propomos uma releitura do romance naturalista brasileiro, evitando a lógica da influência e importaçōes de ideias. Destacamos a função que a literatura naturalista, tanto francesa quanto brasileira, se atribui na cena politica republicana dos dois paises.

Palavras-chave: Romance, naturalismo francês, naturalismo brasileiro.
\end{abstract}

O ano da França no Brasil (2009), em retribuição ao ano do Brasil na França (2005), evidencia, de maneira institucional, os fortes laços históricos e culturais que unem os dois países. As tentativas frustradas da fundação da França Antártica por Villegagnon, no século XVI, no Rio de Janeiro, e da França Equinocial por Daniel de La Touche, no início do século XVII, no Maranhão, constituem marcos fundadores dessa longa história e, como lembra o antropólogo Gilbert Durand no prefácio de Culturas cruzadas; intercâmbios culturais entre França e Brasil, do historiador e sociólogo Mario Carelli, permitiram a simpatia e a amizade entre os dois países, que, ao contrário de Brasil e Portugal, não se baseiam em uma relação de mágoas, comum entre colonizado e colonizador. ${ }^{1}$

Queremos, na esteira do pensamento de Carelli, considerar esse intercâmbio entre as duas culturas como uma troca fecunda para os dois lados,

1. DURAND. Prefácio, p. 11. 
fugindo, assim, de uma leitura que privilegie a lógica da influência-importação que se daria entre um país com uma cultura milenar impositiva e um país jovem, sedento de ideias, mas sem espírito crítico. ${ }^{2}$ Nesse sentido, acreditamos, a título de exemplo, que a vinda da Missão Artística Francesa ao Brasil, em 1816 - chefiada por Joachim Le Breton e integrada por artistas com forte formação neoclássica como Jean-Baptiste Debret, Nicolas-Antoine Taunay, entre outros, que formaram a primeira escola de ensino de arte no Brasil, por decreto de D. João VI -, e a criação da Academia Imperial de Belas Artes, em 1826, não ocorreram de maneira pacífica ou passiva: a Missão Francesa encontra resistência dos artistas portugueses vivendo no Brasil e práticas anteriores oriundas de um "estilo colonial", com as quais tiveram que dialogar. ${ }^{3}$ De retorno à França, Debret, em sua crônica pictórica Viagem pitoresca e bistórica ao Brasil (1834), dá testemunho de o quanto sua estada no Brasil marcara sua visão de mundo e modificara os padrões de sua pintura. ${ }^{4}$

Os exemplos dessa generosa colaboração entre a cultura francesa e a cultura brasileira poderiam se multiplicar. Nesse trânsito intenso, produtos culturais vêm sendo trocados, subvertidos, realimentados, corrompidos e transformados pelos usos que deles se fazem nos contextos histórico-políticos locais dos dois países. Seria preciso atentar para esses contextos de modo a romper com as hierarquias platônicas do modelo (superior) e da cópia (inferior) que falsificam a compreensão do que se fez aqui e lá. No caso da ficção naturalista - que é o foco de interesse deste estudo - poderíamos fazer isso sem deixar de reconhecer a importância de Zola para a escola, aqui e lá. Poderíamos reconhecer a importância do romance francês para a nossa literatura sem cair na armadilha idealista de Afrânio Coutinho, que julga o naturalismo brasileiro "um movimento frustrado" porque não havia aqui um "ambiente propício" para o pleno desenvolvimento da escola.

2. Durand fala ainda "dos fluxos e refluxos pacíficos de duas culturas orgulhosamente autônomas e jamais submissas uma à outra pelos acasos da história”. DURAND. Prefácio, p. 15.

3. A esse respeito cf. LUZ Uma breve história dos Salões de Arte, especialmente o capítulo "Da Europa ao Brasil - a Academia e suas primeiras exposições”, p. 50-60 e também SCHWARCZ. O sol do Brasil; Nicolas-Antoine Taunay e as desventuras dos artistas franceses na corte de d. João.

4. Cf. LUZ. Uma breve história dos Salões de Arte.

5. Cf. COUTINHO. Introdução à literatura no Brasil, p. 229. 
Produzido na França e no Brasil mais ou menos na mesma época últimas décadas do século XIX -, o romance naturalista teve manifestações múltiplas e variadas. Mas no Brasil ele continua sendo lido no contexto estreito das escolas literárias, como manifestação local, nem sempre bem-sucedida, de ideias importadas de Paris, especialmente de Zola e do romance científico. ${ }^{6}$ O objetivo deste estudo é romper com esse modelo de leitura e propor uma reavaliação do romance naturalista a partir de novos vocabulários e pontos de vista críticos.

\section{Por um olhar renovado sobre o naturalismo}

O primeiro nome associado ao naturalismo francês é o daquele que o sociólogo francês Pierre Bourdieu reconhece como sendo o primeiro intelectual: Émile Zola. ${ }^{7}$ No entanto, inúmeros romances de outros escritores imantados pela estética naturalista, tendo participado ou não do grupo literário de Zola, ficam à margem da abordagem dos estudos críticos e, muitas vezes, não cabem na leitura médico-científica veicula pelo ensaio de Zola O romance experimental (1880). A crítica da época, chocada com os temas, reprova a estética que qualifica de "pútrida" - fato que leva Zola a se defender dos ataques, por meio de textos críticos publicados em jornais e revistas, nos quais justifica a estética que propunha.

Os conceitos propostos mais recentemente por David Baguley permitem redimensionar a estética naturalista, expandindo seu horizonte de modos e autores. Citando Yves Chevrel, Baguley reafirma a intenção de "reunir um corpus de textos que, nos anos 1870-1900, foram considerados como possuidores de traços comuns e explicar uns em relação aos outros, utilizando a obra e ação de Zola como referência, mas não como critério único". ${ }^{9}$ Parodiando ainda Brunetière,

6. Para o naturalismo brasileiro como expressão das teorias deterministas europeias, Cf. STRACCIA. O espetáculo de massas na literatura brasileira; QUEIRÓZ JÚNIOR. Preconceito de cor e a mulata na literatura brasileira; DUARTE. A mecânica de um recalque; SUSSEKIND. Tal Brasil, qual romance?

7. Cf. BOURDieu. Les règles de l'art, p. 185-189.

8. Em 1868, após a publicação de Thérèse Raquin (1867) - primeiro romance relevante de Zola que ilustra sua teoria dos temperamentos e anterior à saga Les Rougon-Macquart - o diretor do La Cloche, o republicano Louis Ulbach, chama o romance de "literatura pútrida". Cf. MITTERAND. L'homme de Germinal-1871-1893, p. 534.

9. Chevrel. Citado por BAGUley. Le Naturalisme et ses genres, p. 7. (Tradução dos autores). 
Baguley completa: "trata-se, sobretudo, de escrever a 'história interna' do movimento naturalista, traçar uma 'filiação de textos' e definir as relações dinâmicas entre esses textos e textos-modelos dos quais eles derivam ou se distinguem”. ${ }^{10}$ Buscando demonstrar a literariedade e a genericidade da ficção naturalista, recusa assumir uma abordagem que corrobore o "mito realista da representação direta da vida" assim como o mito da "representação passiva dessa realidade".

Sinteticamente, podemos dizer que Baguley reconhece dois subgêneros naturalistas: o primeiro, cujo modelo estaria nas obras dos irmãos Jules e Edmont de Goncourt, é praticado por Zola em seus romances mais célebres como L'Assommoir (1877), Nana (1880) e Germinal (1885). Marcado por um traço trágico na temática, possui, em geral, uma estrutura canônica de narrativas, com começo, meio e fim bem delineados, com apresentação dos personagens, da problemática, um clímax e um desfecho. Há uma predestinação maior do que a vontade dos personagens, contra a qual eles não têm forças para lutar. Porém, diferentemente das tragédias clássicas, nada há de divino nisso: seus destinos são determinados pela hereditariedade do mal, isto é, pelos erros herdados de gerações passadas, por doenças, influências da educação e do meio, elementos contra os quais estabelecem uma luta darwiniana, ainda que inútil, pela sobrevivência. Tratase do espetáculo de uma queda. ${ }^{12}$

Um segundo subgênero - pouco mencionado quando se fala do naturalismo - seria o naturalismo da desilusão, em que o mal do personagem está relacionado à mediocridade da vida humana e às dúvidas existenciais. Os personagens assumem o papel de espectadores; não há luta, mas resignação. Herdeiro do gênero "cômico" dos romances de Gustave Flaubert, esse subgênero possui uma estrutura mais estática, enquanto que o primeiro é mais objetivo, clínico e dinâmico. Na obra de Zola, por exemplo, L'Assommoir estaria para o naturalismo trágico assim como La joie de vivre (1884) estaria para o naturalismo da desilusão. Nada impede, porém, que em uma mesma narrativa convivam os dois subgêneros. ${ }^{13}$

10. BAGUley. Le Naturalisme et ses genres, p. 7. (Tradução dos autores).

11. BAGULEY. Le Naturalisme et ses genres, p. 6; 8. (Tradução dos autores).

12. Cf. BAGULEY. Le Naturalisme et ses genres, Capítulo IV: "Le modèle tragique."

13. Cf. BAGuley. Le Naturalisme et ses genres, Capítulo V: "La comédie humaine." 
Baguley também não deixa de estudar o modo irônico e o papel central da paródia na estética naturalista. Sua abordagem faz com que possamos melhor compreender o que reúne escritores tão diversos como Émile Zola, Léon Hennique, Guy de Maupassant, Joris-Karl Huysmans, Henri Céard e Paul Alexis sob uma mesma etiqueta (o grupo de Médan), além de tornar possível estender o alcance da estética naturalista a escritores, franceses ou não, como os irmãos Goncourt, Octave Mirbeau, Camille Lemonnier, Paul Adam, Paul Bonnetain, Jules Claretie, entre tantos, responsáveis, assim como Zola, pela circulação dinâmica das obras e a constituição da estética.

Logo, não queremos repisar o terreno já batido das relações entre a literatura naturalista brasileira e seu "modelo" francês, em que se destaca apenas a "importação" dos preceitos médico-científicos da "doutrina" de Zola, sistematizada no célebre ensaio de 1880. ${ }^{14}$ Ora, como afirma David Baguley, esse texto, muito mais do que as bases de uma doutrina estética de uma pretensa "escola naturalista", jamais se cumpriu em todo o seu alcance preceitual, nem mesmo pelo próprio Zola. Compunha, sobretudo, uma jogada publicitária em que o ensaio dava a chave de leitura para o romance que se lançava, Nana, enquanto que este servia como uma espécie de aplicação do Romance experimental. ${ }^{15}$ Esse jogo de autorregulação da obra ${ }^{16}$ constituiu uma estratégia necessária após os violentos ataques ao autor de L'Assommoir - romance que provocou grande escândalo, porém obtendo grande sucesso de público, permitindo a Zola a compra da casa de campo num vilarejo que daria a chancela ao grupo de escritores reunidos em torno dele, com a publicação do volume coletivo, também em 1880, das Soirées de Médan.

14. O volume Le roman expérimental reunia diversos artigos escritos por Zola anteriormente - arrolados na bibliografia desse ensaio. Cf. BECKER et al. Dictionnaire d'Émile Zola; sa vie, son œuvre, son époque suivi du Dictionnaire des Rougon-Macquart, p. 257 e 367-369; MITTERAND. L'homme de Germinal - 1871-1893, p. 503.

15. Cf. Baguley, 1995 , p. 38-43. Para a coincidência de datas de publicação, cf. MITTERAND. L'homme de Germinal - 1871-1893, p. 503.

16. Dominique Maingueneau chama de "espaço associado" (em oposição ao "espaço canônico") os textos pertencentes ao regime elocutivo (dedicatórias, prefácios, comentários, manifestos, debates, etc.) cuja função seria a de regulação "pela qual [o] criador negocia a inserção de seu texto em certo estado do campo e no circuito comunicacional". (Tradução dos autores). MAIGUENEAU. Le discours littéraire; paratopie et scènes d'énonciation, p. 113.

17. Tratamos mais longamente desses temas em CATHARINA. Estética naturalista e configurações da modernidade, p. 105-119. 
A nosso ver, Zola torna-se vítima de si próprio, pois, ao tentar instaurar uma literatura que ele qualificava de moderna e ao associá-la à medicina experimental, ele codificaria a chave de leitura de sua própria obra, fazendo com que outros aspectos igualmente importantes da estética naturalista como, por exemplo, sua hipertrofia descritiva e sua relação com as artes plásticas, fossem relegadas a segundo plano, ou mesmo desconsiderados.

Em outro texto menos comentado pela fortuna crítica do naturalismo, intitulado A República e a literatura, ${ }^{18}$ Zola triangula a relação entre literatura e ciência, que desenvolve no Romance experimental, com a política. Grosso modo, podemos dizer que nesse texto, ao invés de estabelecer homologia entre o literato e o médico-experimentador, Zola estrutura a questão pela comparação entre escritores e políticos republicanos.

Não é inocentemente que o faz, mas estrategicamente. Admitia que, após regimes políticos diversos que se sucederam à Revolução Francesa, as idas e vindas da Monarquia, a Primeira e Segunda Repúblicas e os dois Impérios, o regime republicano deveria finalmente se estabelecer, não como uma imposição, mas como a consequência dos fatos e do amadurecimento político da nação, pois era o regime necessário em épocas de progresso e evolução.

Em A República e a literatura Zola procura afirmar a grande importância da literatura na sociedade e na constituição dos governos. Até então, ela teria sido uma ameaça aos regimes políticos, mesmo em relação à República:

Os governos suspeitam da literatura porque ela é uma força que thes escapa. Um grande artista, um grande escritor os incomoda, apavora, a partir do momento em que eles o sentem escapando da disciplina, armado com um instrumento poderoso. (...) Realeza, Império, República, todos os governos, mesmo os que pretenderam apoiar as letras, rejeitaram os escritores originais e inovadores. Falo principalmente dos tempos modernos, em que o pensamento escrito tornou-se uma arma perigosa. ${ }^{19}$

18. Texto publicado no Figaro de 20 de abril de 1879 - logo, precedendo de pouco a publicação do Romance experimental - antes de ser incorporado pelo editor Charpentier ao volume encabeçado pelo Romance experimental, em 1880. Cf. MITTERAND. L'bomme de Germinal - 18711893 , p. $530-536$.

19. ZOLA. Le roman expérimental. Lettre à la jeunesse. Le naturalisme au théâtre. L'argent dans la littérature. Du roman. De la critique. La République et la littérature, p. 396-397. (Tradução dos autores). 
Zola propõe uma aliança entre os dois campos, o literário e o político, em que a literatura forneça o modelo, baseado na observação e na experimentação. Após reconhecer o pouco apreço da classe política pelos literatos, após ter recusado as relações de dependência que uniam os dois campos (por meio de recompensas, prêmios e pensões), ter exigido que a classe política lhes conceda liberdade ("Façanos livres, e o senhor será um grande ministro" ${ }^{20}$ ), o escritor mostra sua contribuição social através da sua obra, em que construiu uma História natural e social de uma família no Segundo Império, para enfim oferecer a saída para que a República se estabeleça definitivamente, segundo os preceitos do naturalismo:

Nós expusemos a verdade do Império, tornando-nos historiadores desse período histórico, assim como exporemos a verdade da República, quando ela ingressar na nossa história e determinar novos costumes. (...) o naturalismo é uma literatura republicana, se consideramos a República como o governo humano por excelência, baseado na investigação universal, determinado pela maioria dos fatos, enfim, respondendo às necessidades observadas e analisadas de uma nação. ${ }^{21}$

\section{Naturalismo francês, naturalismo brasileiro}

Na França, como afirmava Zola, após a derrocada de Napoleão III, era chegada a hora de a República se estabelecer. No Brasil, o romance naturalista se elabora num momento de transição - bem menos turbulento do que na França, diga-se de passagem - entre o Segundo Reinado e a República. Todos os autores naturalistas brasileiros foram republicanos (e abolicionistas) combativos. Escritores como o paulista Julio Ribeiro, o maranhense Aluísio Azevedo e o cearense Adolfo Caminha entendiam, como Zola, que a política do romance naturalista só poderia ser republicana. Todos eles eram homens de imprensa e, como tais, combatiam pelas causas da liberdade e da República nos jornais das cidades, especialmente no Rio de Janeiro, num trabalho intenso de construção de um dissenso político,

20. ZOLA. Le roman expérimental. Lettre à la jeunesse. Le naturalisme au théâtre. L'argent dans la littérature. Du roman. De la critique. La République et la littérature, p. 404. (Tradução dos autores).

21. ZOLA. Le roman expérimental. Lettre à la jeunesse. Le naturalisme au théâtre. L'argent dans la littérature. Du roman. De la critique. La République et la littérature, p. 401. (Tradução dos autores). 
moral e estético que corria paralelo (e de muitos modos de maneira independente) à construção do republicanismo ligado aos cafeicultores do oeste paulista. Essa diferença era importante porque enquanto o movimento republicano que vinha do interior de São Paulo (e que se tornaria hegemônico) era politicamente conservador e mantinha distância relativa do movimento abolicionista, ${ }^{22}$ o republicanismo dos escritores e jornalistas que praticavam o romance naturalista era uma aspiração que emanava de experiências de diversificação, heterogeneidade e estranhamento próprios das cidades modernas.

Deve nos alertar, nesse contexto, o fato de que eram nordestinos os principais escritores que abraçaram a estética naturalista no Brasil, dando notícia de certa efervescência cultural em capitais provincianas como Recife, São Luís do Maranhão e Fortaleza. Tanto Aluísio Azevedo quanto Adolfo Caminha - para ficarmos com os dois que alcançaram estatuto canônico - eram nordestinos que vão para o Rio de Janeiro para tentar seguir a carreira de escritor e artista, com pouca ou nenhuma rede de proteção social. A impressão de que eles representavam algo de novo na cena da literatura brasileira foi compartilhada por contemporâneos como Urbano Duarte e Adherbal de Carvalho, que saudaram com o grito "Romancistas ao Norte!" o aparecimento do romance O mulato e de Aluísio em $1881 .^{23}$ O grito alertava a intelectualidade brasileira para a evidência de que havia vida inteligente fora do Rio de Janeiro.

De fato, desde a década de 1870 as ideias filosóficas e os pressupostos teóricos que davam sustentação ao romance naturalista brasileiro vinham circulando em cidades do Nordeste. Os notórios exageros de Silvio Romero não lhe retiram (nem de seu grupo na Escola do Recife) o mérito de ter introduzido, pela primeira vez no país, um saber "secular e temporal", afastado de concepções religiosas. ${ }^{24}$ Num país profundamente católico como o Brasil, descartar Deus não era coisa que se fizesse sem contrair inimigos. Mas foi nas duas últimas décadas do século XIX que se escreveram os primeiros romances modernos, sem transcendência, na história da literatura brasileira. ${ }^{25}$ Esse foi o romance naturalista e os modos como ele rompia

22. Cf. BOeHRer. Da monarquia à república. História do Partido Republicano do Brasil.

23. Cf. CARVAlHo. O naturalismo no Brasil, p. 156.

24. Cf. VENTURA. Estilo tropical. História cultural e polêmicas literárias no Brasil 1870-1914, p. 12.

25. Cf. ATHAYDE. Política e letras. 
com a transcendência e com o divino ainda aguardam investigação. Zola e sua obra, é certo, eram lidos e admirados por esses escritores, mas o que tornou possível a emergência de um romance arrojado como O cortiço, em 1890, no Brasil, ultrapassava as influências do romance francês e do cientificismo europeu.

Nas duas últimas décadas do século XIX, alguns escritores nordestinos brasileiros se sentiram confiantes o bastante para introduzir um ponto de vista periférico e/ou marginal na literatura do país. Todas as teorias materialistas, os avanços da ciência e as causas do progresso foram invocados por setores nordestinos que, às vésperas da República, se sentiam excluídos dos debates nacionais. Esses setores eram republicanos porque entendiam que não tinham futuro numa estrutura econômica criada sobre a aliança da monarquia parlamentar com os interesses da monocultura do café, concentrados no sul do país. ${ }^{26}$ O naturalismo, ao pretender construir a ideia da nação como uma entidade composta de pessoas diferentes, reescreveu o Brasil a partir da periferia. ${ }^{27}$ Os escritores naturalistas foram os primeiros a tentar representar a sociedade brasileira "como um todo composto de partes contraditórias, composta de negros, mulatos, mulheres masculinizadas e homossexuais ou homens afeminados". ${ }^{28}$ Tratava-se de um ponto de vista "excêntrico" " que se anunciava e que lutava pelo ingresso no campo literário. Invocar o nome e a autoridade de Zola era uma maneira de abrir portas, entrar no "circuito comunicacional", ganhar leitores (fosse pelo escândalo ou pelo prestígio científico), viabilizar publicações e, quem sabe, uma carreira de escritor na Corte. Mas isso não queria dizer que o modelo não pudesse ser subvertido, transformado ou mesmo corrompido.

Os naturalistas foram os primeiros autores brasileiros que escreveram romances sobre a pobreza, a feiúra e a banalidade do quotidiano nas cidades do país. Se era verdade que O cortiço tinha semelhanças com o romance L'Assommoir (1876), de Zola, também era verdade que havia diferenças, sendo a principal delas "a moralidade aberta" com que o narrador do romance brasileiro descrevia e

26. Cf. TINHORÃO. A província e o naturalismo.

27. Cf. BUENO. Brazilian Naturalism and the Politics of Origin. (Tradução dos autores).

28. BUENO. Brazilian Naturalism and the Politics of Origin, p. 363. (Tradução dos autores).

29. BUENO. Brazilian Naturalism and the Politics of Origin, p. 388. (Tradução dos autores). 
tratava os habitantes das favelas e dos prostíbulos do Rio, a despeito de um verniz cientificista sem o qual nenhum discurso seria levado a sério na segunda metade do século XIX. ${ }^{30}$ No romance, o traço mais característico de relativização moral aparece na celebração da mulatice de Rita Baiana, de sua sexualidade exuberante e alegria de viver. Poderíamos mesmo afirmar que o personagem da mulata, em suas peripécias de erros e acertos, sem nunca pretender ser um modelo de virtudes, configura, no romance, uma teoria do Brasil - a teoria de um país da mestiçagem, da mistura e de seus paradoxos, e da possibilidade da beleza na pobreza. ${ }^{31}$ Tal capacidade de flexibilização (política e moral) emanaria das experiências boêmias da geração de Aluísio e não estaria relacionada ao romance francês. ${ }^{32}$ Enquanto na França a boemia aparece associada mais às batalhas românticas, no Brasil ela coincide com o romance realista/naturalista, a poesia parnasiana e a crise do sistema monárquico.

A cena local era, portanto, de crise política, moral e estética do império brasileiro, de seus aparelhos ideológicos e produtos culturais. Ao longo dos anos turbulentos da década de 1880, chega ao Rio de Janeiro um grupo de rapazes cultos das camadas médias ou populares das províncias (Bilac era o único carioca) que, aos poucos, vão se conhecendo e reunindo nos bares e confeitarias da Rua do Ouvidor, até formar uma boemia com todas as características de rebeldia associadas à boemia parisiense: cabelos compridos, roupas extravagantes, disponibilidade para a nudez em público, múltiplos endereços e uma compreensão moderna da civilização da máquina e do sentido provisório da existência humana que era uma novidade no país. Era uma juventude bem-humorada, desempregada, perigosamente

30. Para as acusações de plágio contra $O$ cortiço, cf. PARDAL MALLET. O cortiço. Para o romance naturalista brasileiro como produção diferenciada do naturalismo francês, cf. MENDES, 2000, 2003 e 2006.

31. Cf. MENDES. O retrato do imperador: negociação, sexualidade e romance naturalista no Brasil.

32. A geração de Aluísio, às vezes chamada de "geração de 89", foi um grupo de jovens escritores boêmios, todos na faixa dos vinte e poucos anos por ocasião da República, que se frequentava com assiduidade nos bares e nas redações dos jornais do Rio antigo. Foram eles, além dos irmãos Artur (1855-1908) e Aluísio Azevedo, Olavo Bilac (1865-1918), Coelho Neto (1864-1934), José do Patrocínio (1854-1905), Paula Nei (1858-1897), Luís Murat (1861-1920), Guimarães Passos (1867-1909) e Pardal Mallet (1864-1894). Para a "moralidade aberta" da experiência boêmia do Rio antigo, cf. OLIVEIRA. Onosarquistas e patafísicos: a boemia literária no Rio de Janeiro fin-de-siècle. 
descrente das religiões e das igrejas e alguns até mesmo descrentes da existência de Deus.

Os boêmios garantiam a sobrevivência com um trabalho irregular nos jornais do Rio. A renda, magra e intermitente, mal dava para pagar o aluguel. Como os jovens boêmios do clássico de Henri Murger, Cenas da vida boêmia (1845), os jovens escritores brasileiros compartilhavam moradias, refeições, roupas e sapatos, amparando uns aos outros na batalha diária de ingresso no campo literário. É surpreendente que em 1890, quando publica O cortiço, Aluísio, um autor já reconhecido, ainda dividisse com Coelho Neto um sobradinho na Rua Conde d'Eu, no centro do Rio. ${ }^{34}$ De 1881 a 1895 - período em que produziu toda a sua obra -, Aluísio enfrentou todas as atribulações de um escritor profissional com pouco dinheiro. ${ }^{35}$ Mesmo que isso o aborrecesse, Aluísio, durante anos, levou a vida de um artista boêmio típico, frequentemente ameaçado de despejo por falta de aluguel, dono de um único terno bom adquirido nos tempos das vacas gordas, diariamente submetido aos caprichos do acaso, que poderia lhe trazer uma refeição, ou não. ${ }^{36}$ Aluísio pode ter reivindicado o título de escritor-cientista, mas ele estava longe, nessa época, de pertencer ao mundo burguês de Zola. Suas pesquisas também eram as andanças pela cidade de um artista boêmio - um "contrabandista", na definição de Maingueneau, "que atravessa[va] as divisões sociais". 37

Embora não fizessem parte dos desvalidos e excluídos da sociedade carioca do final do século XIX, os boêmios (naturalistas, parnasianos ou de outras denominações) às vezes compartilhavam com eles a fome e a penúria, trocando

33. Uma das críticas lançadas contra Aluísio pelos setores conservadores do Maranhão quando saiu $O$ mulato, em 1881, era a de que ele não acreditava na metafísica. Cf. MONTELLO. Aluísio Azevedo e a polêmica de O mulato.

34. Cf. CORReia. A boêmia do meu tempo.

35. Para a vida de Aluísio antes de ingressar na carreira diplomática, cf. MÉRIAN. Aluisio Azevedo. Vida e obra (1857-1913).

36. Sabemos, pelos relatos disponíveis, que Aluísio foi um melancólico que nunca se adaptou às intermitências da vida boêmia de sua juventude. Na sessão de homenagem a Aluísio na Academia Brasileira de Letras, em 1913, quando o escritor morreu, Coelho Neto proferiu discurso em louvor do amigo no qual comentou a insatisfação do escritor com a vida boêmia. E conclui: "Fora, pois, da boemia, porém a renegara mais tarde, dela esquecido e injustamente envergonhado" (Citado por PEIXOTO. Lembranças de Aluísio Azevedo, p. 268).

37. MAINGUENEAU. O contexto da obra literária, p. 35. 
versos, crônicas e artigos de fundo por comida. Quando as coisas apertavam, Aluísio e outros iam para a mansão do Visconde de Barra Mansa, um latifundiário fluminense, rico e solteirão, que gostava da companhia dos boêmios e lhes dava abrigo e refeição em sua mansão em Laranjeiras, às vezes por longos períodos. ${ }^{38}$ Os boêmios viviam numa zona de penumbra, ao mesmo tempo dentro e fora do mundo burguês, ${ }^{39}$ o que lhes permitia um intercâmbio genuíno com as camadas populares da população da cidade e também com setores da elite letrada. Mas isso não queria dizer que eles, às vezes, não fossem esnobes e nem estivessem livres dos preconceitos da classe dominante. Estamos falando de uma experiência urbana, moderna e paradoxal - a boemia - e tentar resolver o paradoxo empobrece nossa compreensão da experiência histórica real.

A marginalidade (no sentido etimológico do termo) exercia, por proximidade contingente, uma atração sobre os boêmios, que com ela se identificavam ocasionalmente. É somente na ficção dos jovens escritores boêmios republicanos que os excluídos começam a pipocar no romance brasileiro. As esferas sociais subalternas também eram o foco de interesse do romance de Zola e a coragem do escritor francês, é claro, animava os escritores brasileiros a escrever romances sobre lavadeiras e moradias populares, como O cortiço, e sobre marinheiros e a zona portuária do Rio, como Bom-Crioulo (1895), de Adolfo Caminha. Para explicar e justificar a decisão de escrever ficções sobre esses sujeitos estranhos e desconhecidos, ${ }^{40}$ os escritores invocavam, também como Zola, o prestígio do discurso científico, que não era moral ou imoral, nem (pretensamente) julgava o que descrevia. Mas a cena política local - a crise do sistema monárquico, a expansão e diversificação da experiência urbana, com o surgimento da boemia e com a grande expansão da imprensa e do comércio de livros, especialmente no Rio de Janeiro ${ }^{41}$ complicava a adesão declarada aos modelos e métodos deterministas de Zola.

38. Cf. MÉRIAN. Aluísio Azevedo. Vida e obra (1857-1913).

39. Cf. SEIGEL. Paris boêmia: cultura, política e os limites da vida burguesa 1830-1930.

40. Brito Broca sugere que o furor causado pelo aparecimento de $O$ cortiço em 1890 se deveu ao fato de que o romance trazia para a literatura brasileira "uma humanidade desconhecida e estranha". Cf. BROCA. Naturalistas, parnasianos e decadistas. Vida literária do realismo ao prémodernismo, p. 130.

41. Para uma avaliação da ficção naturalista no contexto da expansão do mercado editorial carioca no final do século XIX, cf. EL FAR. Páginas de sensação. Literatura popular e pornográfica no Rio de Janeiro (1870-1924). 
Na França, como dissemos, Zola criou uma camisa de força interpretativa para sua própria obra ao associar o romance naturalista à medicina experimental, fazendo com que outros aspectos da estética naturalista fossem ignorados pela tradição crítica, tanto no romance dele como no de outros autores do período. Do mesmo modo, no Brasil alguns autores e romances do final do século XIX foram esquecidos porque não se encaixavam no perfil cientificista exclusivamente associado à escola. Esta é uma das razões que possivelmente explica o desinteresse da crítica pela obra de Coelho Neto, romancista fecundo e companheiro das jornadas boêmias dos jovens escritores republicanos na Rua do Ouvidor e adjacências, nas décadas de 1880-90. Mas esta é só uma das razões. O esquecimento de Coelho Neto tem razões complexas e alegar que ele foi vítima de uma compreensão superficial da estética naturalista não esgota a questão. ${ }^{42}$ Ele foi também uma das baixas do modernismo, que orquestrou uma campanha bem-sucedida de difamação do escritor, associando-o a uma visão afrancesada e superficial da realidade, sem fundo social, que teria sido sepultada pelos paulistas em $1922{ }^{43}$ Entretanto, vários aspectos da estética naturalista sem relação direta com a chave cientificista, conforme arrolados por Baguley, ajudam-nos a compreender e apreciar alguns romances importantes de Coelho Neto, tais como Miragem (1895), A conquista (1899) e Fogo fátuo (1929), ampliando e diversificando o corpus da ficção naturalista no Brasil.

São romances ligados às experiências da juventude boêmia do autor, mais próximos do romance de Flaubert do que do romance de Zola, desprovidos do verniz cientificista de O cortiço e Bom-Crioulo e antes empenhados em narrar não os triunfos da civilização moderna (como o método experimental de Zola parecia sugerir), mas suas desilusões. O naturalismo da desilusão, de que fala Baguley, aparece especialmente em Miragem, como sugere o próprio título do romance. Nele Coelho Neto narra a proclamação da República a partir do ponto de vista de um soldado tuberculoso que passa mal e desmaia justamente na hora em que, ao lado dele, Deodoro passava a cavalo e em triunfo pela Rua do Ouvidor no dia 15 de novembro. A história do soldado Tadeu é uma antiepopéia de fracassos e frustrações que termina com sua morte. Nada é alcançado, nada é realizado, nada é compreendido. O que vemos operar aqui é a proposição radical de rompimento

42. Para um estudo esclarecedor sobre Coelho Neto e sua obra na tradição crítica brasileira, cf. LOPES. No purgatório da crítica: Coelho Neto e seu lugar na história da literatura brasileira.

43. Para uma crítica negativa típica da obra de Coelho Neto, cf. PEREIRA. Prosa de ficção (de 1870 a 1920). História da literatura brasileira. 
com a culminância (de sentido) do épico, uma estratégia narrativa que só seria realmente compreendida e apreciada no modernismo.

O mesmo se verifica em A conquista e Fogo fátuo, com suas estruturas circulares e circunstanciais, que não concluem nada e nem chegam a lugar nenhum. A conquista é possivelmente o romance mais conhecido e citado de Coelho Neto, mas ele aparece mais como fonte primária de pesquisa historiográfica sobre a vida literária carioca do final do século XIX do que como narrativa ficcional. Como tal, o título do romance, que reverbera intenções épicas, só pode ser uma ironia porque nada (ou quase nada) é conquistado na narrativa. Tanto A conquista como Fogo fátuo têm um regime temporal que suprime os nexos de consecução e causalidade da narrativa. Ambos os romances podem ser lidos e apreciados como uma série de crônicas sobre o Rio antigo e a vida boêmia. A organização dos capítulos é circunstancial, como um dobrar aleatório de esquinas. O leitor é como um andarilho (boêmio) que atravessa a cidade. Em Fogo fátuo, o capítulo XI descreve eventos (o encilhamento) posteriores aos que descreve o capítulo XII (o baile da Ilha Fiscal e o 15 de novembro) operando um rompimento com a cronologia, com o historicismo, e mais importante, com a causalidade e a teleologia, sugerindo, portanto, a falta de relação lógica entre os eventos e de finalidade das coisas.

O naturalismo da desilusão e o estudo da experiência boêmia do Rio antigo nos ajudam a perceber o que os jovens escritores republicanos tinham em comum, para além das escolas literárias. Também ganha relevo sob essa ótica o romance de Pardal Mallet, outro companheiro das jornadas boêmias das décadas de 1880-90 no Rio e outro autor esquecido. Em Hóspede (1887), Pardal Mallet narra a história de um adultério que não se concretiza, em contraposição aos romances de adultério tão comuns no século XIX. Nada acontece. Nada de relevante acontece também no romance Lar (1888), com sua descrição monótona do quotidiano banal de uma família pequeno-burguesa no Rio de Janeiro do final do século XIX. Esses romances de Pardal Mallet e de Coelho Neto inscrevem a transitoriedade e o provisório em suas estruturas profundas (e aqui incluiríamos também O cortiço); são libelos contra o definitivo, que louvam o acaso e o dia a dia prosaico da existência. Na frase emblemática de Neiva, em Fogo fátuo: "Não tenho casa, como não tenho esposa nem livro, tudo transitório: o hotel, a amante e o jornal." ${ }^{44}$

44. COELhO NETO. Fogo fátuo, p. 48. 


\section{Considerações finais}

No momento em que alguns decretam o fim da literatura, os estudos das cenas literárias do passado parecem carecer de credibilidade. O prestígio de que a literatura gozava no século XIX e na primeira metade do século XX, na França e no Brasil, impulsionado pelos meios de divulgação, sobretudo a imprensa, enfraqueceu-se, restringindo-se hoje a um campo restrito e particular de atuação. Essa supremacia foi assumida pelo espaço multimidiático em que outros discursos - a propaganda, o cinema, a música popular - ocupam o centro da discussão dos problemas sociais e das questões políticas, ao passo que a literatura se fechou sobre o próprio campo, concentrando-se em seus próprios arquivos. Hoje, são esses discursos que ditam modelos de comportamento, outrora oferecidos pela literatura, ao propor modos de apreender a realidade. A ausência de polêmicas literárias atuais indica essa perda de força simbólica da literatura nas disputas da sociedade. ${ }^{45}$ Nesse sentido, o status do crítico literário também perde em função social. A apreensão dos textos do passado, pelos leitores atuais, na lógica atual do campo, impõe uma visão em que a importância da literatura se atenua, sobretudo em relação às questões sociais, mas também estéticas, que encenavam. Devemos então admitir que, dentro de alguns anos, não seremos mais capazes de ler (e compreender) textos como Madame Bovary, A pata da gazela, A mulher de 30 anos e quase toda a literatura do passado? Não seria já essa a realidade que encontramos na formação das novas gerações nascidas após o advento do mundo multimidiático?

Para que não caiamos no anedótico nem na análise superficial de algo que não interessaria mais, as questões levantadas neste ensaio acerca das relações entre a literatura naturalista no Brasil e na França devem ser encaradas dentro da lógica relacional do campo à época, dando destaque à sedimentação do regime republicano nos dois países. Com o passar do tempo, tendo os valores republicanos e democráticos ocupado o proscênio da cena política mundial, a importância da literatura naturalista parece se perder, quando desvinculada de seu contexto de produção. No entanto, vale lembrar que a força de literatura de Zola forneceu-lhe capital social suficiente para intervir em assuntos de Estado, como foi sua participação no "caso Dreyfus”, que mobilizou toda a França.

45. Cf. MAingueneau. Contre Saint Proust ou la fin de la Littérature. 
No Brasil, os autores que abraçaram a estética naturalista o fizeram no contexto de uma experiência boêmia nos anos turbulentos da crise do sistema monárquico, a das lutas por um país mais plural e democrático. Tais lutas atravessaram a década de 1880 e incluíram a campanha abolicionista, de que os boêmios foram protagonistas, reunidos em torno da figura lendária do jornalista negro José do Patrocínio. Patrocínio deu emprego a todos os rapazes no jornal $A$ Cidade do Rio, que ele dirigia e que se tornaria um porta-voz dos setores letrados que lutavam por um país da diversidade e da pluralidade.

Os jovens escritores republicanos também se aventuraram na publicação de periódicos oposicionistas por conta própria, tais como os jornais $A$ Rua e O meio, em 1889, e o radical O Combate, em 1892. Nos dois primeiros, escreviam artigos contra a monarquia. Nos intervalos, imaginavam e publicavam romances naturalistas sobre o feio e o banal. Em O Combate, escreviam artigos contra o governo Floriano Peixoto, que acabou por mandar fechar o jornal e prender os escritores boêmios. Bilac conseguiu fugir para Ouro Preto, mas quando voltou ao Rio recebeu ordem de prisão ao desembarcar do trem na Central. Coelho Neto abaixou o tom e ficou no Rio, optando por fazer críticas veladas ao governo republicano em crônicas de jornais. Pardal Mallet e Patrocínio foram presos e exilados no Pará. Era o fim da boemia do Rio antigo, mas não do romance naturalista brasileiro, que agora tinha plenas razões para ficcionalizar a desilusão.

46. Para um estudo sobre os jornais dos escritores republicanos, cf. SILVA. Entre a pena e a espada: literatos e jacobinos nos primeiros anos da República (1889-1895). Para as atribulações de Patrocínio e dos boêmios nos primeiros anos da República, cf. MAGALHÃes JUNIOR. A vida turbulenta de José do Patrocínio. 


\section{Naturalism, here and là-bas}

Abstract: The aim of this essay is to present a re-reading of the Brazilian naturalist novel outside the logic of influence and the importation of ideas. The essay highlights the connection between naturalist fiction and the republican scene, both in France and in Brazil.

Keywords: Novel, French Naturalism, Brazilian Naturalism.

$$
\text { Referências }
$$

ATHAYDE, Tristão de. Política e letras. In: CARDOSO, Vicente Licínio. À margem da bistória da república. Recife: Fundação Joaquim Nabuco/Editora Massangana, 1990. p. 209-255.

BAGULAY, David. Le Naturalisme et ses genres. Paris: Nathan, 1995.

BECKER, Colette et al. Dictionnaire d'Émile Zola; sa vie, son œuvre, son époque suivi du Dictionnaire des Rougon-Macquart. Paris: Robert Laffont, 1993.

BOEHRER, George C. Da monarquia à república. História do Partido Republicano do Brasil. Belo Horizonte: Editora Itatiaia, 2000.

BOURDIEU, Pierre. Les règles de l'art. Paris: Seuil, 1992.

BROCA, Brito. Naturalistas, parnasianos e decadistas. Vida literária do realismo ao pré-modernismo. Campinas: Editora Unicamp, 1991.

BUENO, Eva Paulino. Brazilian naturalism and the politics of origin. $M L N$, Baltimore, v. 107, n. 2, p. 363-395, 1992.

CARELLI, Mario. Culturas cruzadas: intercâmbios culturais entre França e Brasil. Trad. Nícia Adan Bonatti. Campinas: Papirus, 1994.

CARVAlHO, Adherbal de. O naturalismo no Brasil. Maranhão: Livraria Contemporânea, Júlio Ramos e C. Editores, 1894.

CATHARINA, Pedro Paulo G. F. Estética naturalista e configurações da modernidade. In: MELlO, Celina Maria Moreira; CATHARINA, Pedro Paulo G. F. (Org.). Crítica e movimentos estéticos: configurações discursivas do campo literário. Rio de Janeiro: 7Letras, 2006. p. 105-136.

COElho NETO, Henrique. Fogo fátuo. Porto: Lello \& Irmãos, 1929.

CORREIA, Leôncio. A boêmia do meu tempo. Curitiba: Edição do Estado do Paraná, 1955.

COUTINHO, Afrânio. Introdução à literatura no Brasil. Rio de Janeiro: Civilização Brasileira, 1976.

DEBRET, Jean-Baptiste. Caderno de viagem. Texto e organização de Julio Bandeira. Rio de Janeiro: Sextante, 2006. 
DUARTE, Eduardo de Assis. A mecânica de um recalque. 1978. 220 fl. Dissertação (Mestrado em Letras). Pontifícia Universidade Católica, Rio de Janeiro, 1978.

DURAND, Gilbert. Prefácio. In: CARELLI, Mario. Culturas cruzadas: intercâmbios culturais entre França e Brasil. Trad.: Nícia Adan Bonatti. Campinas: Papirus, 1994. p. 11-16.

EL FAR, Alessandra. Páginas de sensação. Literatura popular e pornográfica no Rio de Janeiro (1870-1924). São Paulo: Cia. das Letras, 2004.

FARIA, João Roberto. Idéias teatrais. O século XIX no Brasil. São Paulo: Perspectiva /FAPESP, 2001.

LOPES, Marcos Aparecido. No purgatório da crítica: Coelho Neto e seu lugar na história da literatura brasileira. Dissertação de Mestrado. Campinas: UNICAMP, 1997.

LUZ, Angela Ancora da. Uma breve história dos Salões de Arte. Rio de Janeiro: Caligrama, 2005.

MAGAlHÃES JUNIOR, Raimundo. A vida turbulenta de José do Patrocínio. Rio de Janeiro: INL, 1972.

MAINGENEAU, Dominique. O contexto da obra literária. São Paulo: Martins Fontes, 2001.

MAINGENEAU, Dominique. Le discours littéraire; paratopie et scènes d'énonciation. Paris: Armand Colin, 2004.

MAINGEnEAU, Dominique. Contre Saint Proust ou la fin de la Littérature. Paris: Belin, 2006.

MENDES, Leonardo. Naturalismo com aspas: Bom-Crioulo de Adolfo Caminha, a homossexualidade e os desafios da criação literária. Revista Gragoatá, Niterói, Universidade Federal Fluminense, v. 14. p. 29-44, 2003.

MENDES, Leonardo. As qualidades da incorreção: o romance naturalista no Brasil. In: MELLO, Celina Maria Moreira de; CATHARINA, Pedro Paulo Garcia Ferreira (Org.). Crítica e movimentos estéticos: configurações narrativas do campo literário. Rio de Janeiro: 7Letras, 2006. p. 137-165.

MENDES, Leonardo. O retrato do imperador: negociação, sexualidade e romance naturalista no Brasil. 7. Porto Alegre: EDIPUCRS, 2000. (Coleção Memória das Letras).

MENDES, Leonardo. Rita Baiana: nação e sexualidade em O cortiço. In: AZEVEDO FILHO, Deneval Siqueira de; MAIA, Rita Maria de Abreu (Org.). Livros e idéias: ensaios sem fronteiras. São Paulo: Arte \& Ciência, 2004. p. 115-128.

MÉRIAN, Jean-Yves. Aluísio Azevedo. Vida e obra (1857-1913). Rio de Janeiro: Espaço e Tempo, 1988.

MITTERAND, Henri. Zola. L'homme de Germinal - 1871-1893. T. II. Paris: Fayard, 2001.

MONTEllo, Josué. Aluísio Azevedo e a polêmica de O mulato. Rio de Janeiro: José Olympio, 1975.

OLIVEIRA, Diogo de Castro. Onosarquistas e patafísicos: a boemia literária no Rio de Janeiro fin-de-siècle. Rio de Janeiro: 7Letras, 2008.

PARDAL MALlET, João Carlos de Medeiros. O cortiço. In: AZEVEDO, Aluisio. Aluisio Azevedo: ficção completa em dois volumes. Rio de Janeiro: Nova Aguilar, 2005. v. 1. p. 83-89. 
PEIXOTO, Afrânio. Lembranças de Aluísio Azevedo. In: Poeira da estrada. Ensaios de crítica e de história. São Paulo: Cia. Editora Nacional, 1944. p. 258-269. PEREIRA, Lucia Miguel. Prosa de ficção (de 1870 a 1920). História da literatura brasileira. Belo Horizonte: Itatiaia, 1988.

QUEIRÓZ JÚNIOR, Teófilo de. Preconceito de cor e a mulata na literatura brasileira. São Paulo: Ática, 1975.

SCHWARCZ, Lilia Moritz. O sol do Brasil; Nicolas-Antoine Taunay e as desventuras dos artistas franceses na corte de d. João. São Paulo: Companhia das Letras, 2008.

SEIGEL, Jerrold. Paris boêmia: cultura, política e os limites da vida burguesa 18301930. Porto Alegre: L\&PM, 1992.

SILVA, Ana Carolina Feracin da. Entre a pena e a espada: literatos e jacobinos nos primeiros anos da República (1889-1895). Dissertação de mestrado. Campinas: Unicamp, 2001.

STRACCIA, Carlos (Org.). O espetáculo de massas na literatura brasileira. São Paulo: Selimunte, 1992.

SUSSEKIND, Flora. Tal Brasil, qual romance? Rio de Janeiro: Achiamé, 1984.

TINHORÃO, José Ramos. A província e o naturalismo. Rio de Janeiro: Civilização Brasileira, 1966.

VENTURA, Roberto. Estilo tropical. História cultural e polêmicas literárias no Brasil 1870-1914. São Paulo: Companhia das Letras, 1991.

ZOLA, Émile. Le roman expérimental. Lettre à la jeunesse. Le naturalisme au théâtre. L'argent dans la littérature. Du roman. De la critique. La République et la littérature. $5^{\mathrm{e}}$ éd. Paris: Charpentier, 1881. 